\title{
The Ableism of Quality of Life Judgments in Disorders of Consciousness: Who Bears Epistemic Responsibility?
}

\section{Joel Michael Reynolds}

To cite this article: Joel Michael Reynolds (2016) The Ableism of Quality of Life Judgments in Disorders of Consciousness: Who Bears Epistemic Responsibility?, AJOB Neuroscience, 7:1, 59-61, DOI: 10.1080/21507740.2016.1150911

To link to this article: http://dx.doi.org/10.1080/21507740.2016.1150911

曲 Published online: 04 Apr 2016.

Submit your article to this journal $₫$

Џ Article views: 26

Q View related articles $₫$

View Crossmark data $\nearrow$ 
resources. In this regard, while I agree with Johnson about the need for more research around quality of life of patients with DoC to avoid misplacement of expectations and make more informed decisions around life-sustaining treatment, I would argue that we first need more attention to the values at stake.

Values not only guide selection and evaluation of behavior, people, and events; they also enable groups and individuals to cope with reality as they "cognitively transform the necessities inherent in human existence and express them in the language of specific values about which they can then communicate" (Schwartz 1994, 21). Values also affect the means that are used to achieve those ideals and goals (Cabrera 2014); that is to say, values affect the way we use, develop, and regulate technology, as well as how we understand consciousness and associated consciousness disorders. Equally, new methods and technologies used in DoC diagnosis and prognosis can potentially affect our values regarding those issues. Every new method and technology presents us with a different way to assess available facts, to weigh evidence, and to perceive a given phenomena. An illustrative example is the way in which functional magnetic resonance images have been contested in court cases, since those images create the feeling of certainty to the untrained eye they are seen as biasing court decisions.

Taking the preceding points into consideration, we can see why a value analysis can help reveal the role that values (both epistemic and nonepistemic) play in weighing the consequences faced in both diagnosis and prognosis of DoC, usefully illuminating extant social structures and commercial market interests, and might help us to better deal with uncertainties encountered in the diagnosis and prognosis of DoC.

\section{REFERENCES}

Cabrera, L. Y. 2014. How does enhancing cognition affect human values? How does this translate into social responsibility?. In Current topics in behavioral neurosciences, ed. G. Lee, J. Illes, and F. Ohl, Vol. 19, 223-41. Berlin, Germany: Springer.

Cabrera Trujillo, L. Y. and S. Engel-Glatter 2014. Human-animal chimera: A neuro driven discussion? Comparison of three leading european research countries. Science and Engineering Ethics 21(3): 595-617.

Hempel, C. G. 1965. Aspects of scientific explanation and other essays in the philosophy of science. New York, NY: Macmillan.

Johnson, L. S. M. 2016. Inference and inductive risk in disorders of consciousness. AJOB Neuroscience 7(1): 35-43.

Schwartz, S. H. 1994. Are there universal aspects in the structure and contents of human values? Journal of Social Issues 50:19-45.

Streiffer, R. 2010. Chimeras, moral status, and public policy: Implications of the abortion debate for public policy on human/nonhuman chimera research. Journal of Law, Medicine $\mathcal{E}$ Ethics 38(2): 238-50.

Warren, M. A. 1973. On the moral and legal status of abortion. Monist 57(1): 43-61.

Żuradzki, T. 2014. Moral uncertainty in bioethical argumentation: A new understanding of the pro-life view on early human embryos. Theoretical Medicine and Bioethics 35(6): 441-57.

\section{The Ableism of Quality of Life Judgments in Disorders of Consciousness: Who Bears Epistemic Responsibility?}

\section{Joel Michael Reynolds, Emory University}

After addressing significant inductive risks involved in judgments concerning patients with disorders of consciousness (DOC), Johnson argues that the best approach is to allow "patients or their families/surrogates to make decisions regarding treatment and nontreatment" (Johnson 2016, 40). The sole qualification Johnson places on their decision making is that they are educated about and "understand the uncertainties of diagnosis and prognosis" (40). Drawing upon research in empirical psychology and philosophy of disability, I argue that this educational qualification is insufficient to address systemic ableism in quality-of-life judgments. I propose that substantive disability education supplement stakeholders' diagnostic education in decision making for DOC patients. 
Johnson argues against inference by analogy from the experience of conscious, severely disabled individuals to unconscious or minimally conscious patients, yet such inference is integral to decision making concerning DOC patients. This is because part of the logic of withholding lifesaving treatment (LST) is not simply that a patient might be conscious and suffering, but also, as Johnson notes, that "if she survives, [she] may be left in a severely disabled condition, or in a DOC" (40). Whether or not the aforementioned form of inference by analogy is reliable to hypothesize about the experience of someone with a DOC, the possibility of being in some type of "severely disabled condition" is, on Johnson's own account, still essential to decision making concerning DOC patients. This means that assumptions concerning the experience of living with a disability, severe or otherwise, play a determinate, if not central role in these judgments.

\section{DISABILITY AND THE DIACHRONICITY OF FLOURISHING}

Longitudinal research on psychosocial adjustment in empirical psychology suggests that transitioning from an ablebodied state to one of relative impairment presents unique challenges related to flourishing, especially when the new state involves chronic pain or illness (Felton, Revenson, and Hinrichsen 1984; Schmidt et al. 2012). Yet, this research also suggests that even in cases of extreme transition, people typically come to find new forms of flourishing and desire to continue living, especially as pain catastrophizing subsides. Because pain catastrophizing is significantly associated with pain intensity and psychological adjustment, one can conjecture that in cases of severe disability not concomitant with pain or chronic illness such positive outcomes are even more likely (Engel et al. 2013).

The belief that one would rather die than live disabled is widespread across Western culture and is central to the prevalence of disability stigma and ableism (Milani 1997). I here define ableism as the normative assumption that the "standard" or "normal" able-body is, ceteris paribus, in and of itself better than nonstandard or abnormal forms. As a dominant ideology, ableism structures built and social environments and thereby forms part of the implicit background knowledge out of which and through which judgments are made (Thomas 2007). If research on psychosocial adjustment suggests people not only cope but even flourish with various forms of disability, then, contrary to popular belief and ableist intuitions, the baseline assumption should be that people would prefer to live disabled rather than die. They would prefer this even under comparatively restricted conditions, even with comparatively intense suffering, and even if it is a case of "severe disability." (The qualification "severe" is vague and warrants suspicion when used as if it picks out a coherent set of phenomena. Its uncritical usage in bioethical literature is a problem that deserves much more treatment, but I cannot address it here).

\section{EPISTEMIC EFFECTS OF DISABILITY STIGMA AND MISJUDGMENT}

A number of philosophers of science maintain that values affect our trust in the testimony of others as well as the evidential thresholds needed for justified epistemic judgments (Miller 2014). Due to widespread ableism, people with disabilities experience both hermeneutical and testimonial injustice (Fricker 2007). That is to say, the conditions under which the testimony of people with disabilities is given value create epistemic disadvantages on both systemic and individual levels. There is thus a low likelihood that stakeholders will accurately judge the value of a life and its forms of flourishing as these relate to diagnostic outcomes that involve an impaired state (Campbell 2009). Given these disadvantages, the inductive risk of an ablebodied person assessing the level of flourishing of someone living with disability is high.

\section{MAINTAINING EPISTEMIC INJUSTICE THROUGH APPEALS TO REASON}

It is thus misleading when Johnson states that "reasonable people will differ about what counts as an acceptable life" (40) as though the reasonableness or the metrics in question are themselves neutral. On the contrary, sustained criticism and correctives are called for and especially so when they involve well-known asymmetries of epistemic power, such as the situations under discussion. As I argued above, there is evidence to suggest that the metric of acceptable life according to "reasonable people" is prejudicially slanted against people with disabilities in empirically problematic, if not indefensible ways. It is important to bear in mind that the epistemic disadvantages people with disabilities face have played a role in the generation and justification of horrifying injustices across history, from social ostracization and institutionalization to widespread abuse and forced sterilization, among other eugenic practices. As regards the type of cases in question, this epistemic disadvantage can lead stakeholders to withdraw LST when, with better education about disability experience, they otherwise might not. When that decision is made without corrective educational measures, ableism and the widespread epistemic disadvantage people with disabilities experience are determining factors in a death and, insofar as that disadvantage is unjust, an unjust death. Such injustices can be addressed at least in part by further education, information, and understanding about experiences of disability.

\section{ETHICS AND DISABILITY EDUCATION}

I have argued that phenomenological approaches as well as literary approaches to disability provide unique insights for both medical practice and theory (Reynolds 2014). However, one might respond that health care providers as well as other stakeholders in decisions over patients with DOC have limited time and resources to engage with 
various forms of knowledge about the experience of disability. This balance of constraint and judiciousness is ultimately an ethical question. Eva Kittay has suggested that a contributing factor to the devaluing and disparagement of disability is a failure to practice what she calls epistemic modesty: know what one does not know (Kittay 1999). Able-bodied experience does not automatically afford one insight into disabled experience; on the contrary, it is likely to misunderstand, misjudge, and mischaracterize that experience. The corollary to this epistemic virtue is the prescription to learn more about the experience of disability and to correctively value such experience in light of the epistemic disadvantage under which it has historically and still today operates.

While Johnson astutely notes the ableist prejudice "to underestimate the actual quality of life experienced by people who have disabilities" (38), measures to combat this prejudice are not part of Johnson's proposals. I have argued that substantive disability education is a necessary, though not thereby sufficient, way to combat such prejudice. To be clear, it is not simply that disability education ought to be "added" as an optional supplement to other forms of education in order to promote good decision making in these cases; it is that stakeholders cannot make well-informed judgments concerning the uncertainties of diagnosis and prognosis if the nature of those diagnostic and prognostic outcomes relies upon a misunderstanding of the lived experience to which those outcomes relate. Without further education about the lived experience of disability and given the inductive risk of quality-of-life assessment concerning disability, surrogates' judgments are not likely to result in decisions that maximally respect the autonomy of patients and accord with their wishes. Given this state of affairs, stakeholders have an epistemic responsibility to educate themselves about disability experience. Disability education is necessary and critical for judgments over the care and treatment of patients with DOC and, mutatis mutandis, all patients with disabilities.

\section{REFERENCES}

Campbell, F. K. 2009. Contours of ableism: The production of disability and abledness. New York, NY: Palgrave Macmillan.

Engel, J. M., S. Wilson, S. T. Tran, M. P. Jensen, and M. A. Ciol. 2013. Pain catastrophizing in youths with physical disabilities and chronic pain. Journal of Pediatric Psychology 38(2): 192-201. http:/ / dx.doi.org/10.1093/jpepsy/jss103.

Felton, B. J., T. A. Revenson, and G. A. Hinrichsen. 1984. Stress and coping in the explanation of psychological adjustment among chronically ill adults. Social Science \& Medicine 18(10): 889-98. http://dx.doi.org/10.1016/0277-9536(84)90158-8.

Fricker, M. 2007. Epistemic injustice: Power and the ethics of knowing. New York, NY: Oxford University Press.

Johnson, L. S. M. 2016. Inference and inductive risk in disorders of consciousness. AJOB Neuroscience 7(1): 35-43.

Kittay, E. F. 1999. Love's labor: Essays on women, equality, and dependency, thinking gender. New York, NY: Routledge.

Milani, A. 1997. Better off dead than disabled?: Should courts recognize a "wrongful living" cause of action when doctors fail to honor patients' advance directives? Washington and Lee Law Review 54(1): 149.

Miller, B. 2014. Catching the WAVE: The weight-adjusting account of values and evidence. Studies in History and Philosophy of Science 47:69-80. http://dx.doi.org/10.1016/j.shpsa.2014.02.007.

Reynolds, J. M. 2014. Feeding upon death: Pain, possibility, and transformation. In Jahrbuch Literatur und Medizin, eds. F. Steger and B. von Jagow, Band 6, 135-54. Universitätsverlag Winter.

Schmidt, S. D., T. O. Blank, K. M. Bellizzi, and C. L. Park. 2012. The relationship of coping strategies, social support, and attachment style with posttraumatic growth in cancer survivors. Journal of Health Psychology 17(7): 1033-40. http://dx.doi.org/10.1177/ 1359105311429203.

Thomas, C. 2007. Sociologies of disability and illness: Contested ideas in disability studies and medical sociology. New York, NY: Palgrave Macmillan.

\section{Avoiding the Worst Possible Outcome for Ambiguously Conscious Patients}

Matthew Reisman, Albert Einstein College of Medicine

In "Inference and Inductive Risk in Disorders of Consciousness," Johnson (2016) proposes that health care providers should "wait for more certainty" before withdrawing life-sustaining treatment from patients with disorders of consciousness (DOC). ${ }^{1}$ This, she argues, would allow surrogates to make better informed and less rushed decisions that are more in line with a DOC patient's preferences, so as to avoid causing the "worst

Address correspondence to Matthew Reisman, Albert Einstein College of Medicine, 75 East 208th Street, 3rd Floor, Bronx, NY 10467, USA. E-mail: reisman.matt@gmail.com

1. Due to space constraints, I do not distinguish between disorders of consciousness. 